\title{
Erratum to: The effect of climate variability on urinary stone attacks: increased incidence associated with temperature over $18{ }^{\circ} \mathrm{C}$ : a population-based study
}

\author{
Hyoung Keun Park · Sang Rak Bae · Satbyul E. Kim • \\ Woo Suk Choi $\cdot$ Sung Hyun Paick $\cdot$ Kim Ho $\cdot$ \\ Hyeong Gon Kim • Yong Soo Lho
}

Published online: 6 January 2015

(C) Springer-Verlag Berlin Heidelberg 2015

\section{Erratum to: Urolithiasis}

DOI 10.1007/s00240-014-0741-5

The original version of this article unfortunately contained a mistake. The affiliation of the following author Hyoung Keun Park, Woo Suk Choi, Sung Hyun Paick, Hyeong Gon Kim and Yong Soo Lho are incorrect. The correct affiliation should be:

Department of Urology, Konkuk University School of Medicine, 120-1, Neung-Dong-Ro, Gwangjin-Ku, Seoul 143-729, Korea

The online version of the original article can be found under doi:10.1007/s00240-014-0741-5.

H. K. Park · W. S. Choi $(\bowtie) \cdot$ S. H. Paick · H. G. Kim · Y. S. Lho Department of Urology, Konkuk University School of Medicine, 120-1, Neung-Dong-Ro, Gwangjin-Ku, Seoul 143-729, Korea e-mail: 20140123@kuh.ac.kr

H. K. Park

e-mail: 20110075@kuh.ac.kr

S. H. Paick

e-mail: 20030010@kuh.ac.kr

H. G. Kim

e-mail: 20040097@kuh.ac.kr

S. R. Bae

Department of Urology, The Catholic University of Korea,

Uijeongbu St. Mary's Hospital, Uijeongbu, Gyeonggi-Do, Korea

e-mail: robinbae97@nate.com

\section{S. E. Kim $\cdot$ K. Ho}

Department of Epidemiology and Biostatistics, School of Public Health, The Institute of Health and Environment, Seoul National

University, Seoul, Korea

e-mail: estella326@snu.ac.kr

K. Ho

Y. S. Lho

e-mail: hokim@snu.ac.kr

e-mail: 19890010@kuh.ac.kr 